\title{
SPATIO-TEMPORAL CHANGE OF VEGETATION COVERAGE AND ITS DRIVING FORCES BASED ON LANDSAT IMAGES: A CASE STUDY OF CHANGCHUN CITY
}

\author{
Lu DONG $^{1,2}$, Hailing JIANG ${ }^{2}$, Lingbin YANG ${ }^{1, *}$ \\ ${ }^{1}$ School of Geographical Science, Northeast Normal University, Changchun 130024, China- (dongl170, \\ yanglb872)@nenu.edu.cn \\ ${ }^{2}$ School of Tourism and Geographical Science, Jilin Normal University, Siping 136000, China- hai.ling.1986@163.com
}

KEY WORDS: Vegetation Coverage, NDVI, Spatio-Temporal Variations, Remote Sensing, Changchun

\author{
Commission III , WG III/7
}

\begin{abstract}
:
Based on the Landsat images in 2006, 2011 and 2015, and the method of dimidiate pixel model, the Normalized Difference Vegetation Index (NDVI) and the vegetation coverage, this paper analyzes the spatio-temporal variation of vegetation coverage in Changchun, China from 2006 to 2015, and investigates the response of vegetation coverage change to natural and artificial factors. The research results show that in nearly 10 years, the vegetation coverage in Changchun dropped remarkably, and reached the minimum in 2011. Moreover, the decrease of maximum NDVI was significant, with a decrease of about $27.43 \%$, from 2006 to 2015 . The vegetation coverage change in different regions of the research area was significantly different. Among them, the vegetation change in Changchun showed a little drop, and it decreased firstly and then increased slowly in Yushu, Nong'an and Dehui. In addition, the temperature and precipitation change, land reclamation all affect the vegetation coverage. In short, the study of vegetation coverage change contributes scientific and technical support to government and environmental protection department, so as to promote the coordinated development of ecology and economy.
\end{abstract}

\section{INTRODUCTION}

The vegetation is an essential part in the whole geographical environment, and it is responsible for the important task of material and energy exchange between land and atmosphere. People can use remote sensing technology and Geographic Information System (GIS) to monitor and obtain vegetation health status, coverage changes and other related information, so as to study its relationship with the ambient environmental factors and the comprehensive effect. Vegetation research has important implications for the study of global climate change, and it is beneficial to promote ecological regulation.

In vegetation remote sensing, the Normalized Difference Vegetation Index (NDVI) can indicate the growth, coverage and nutrition information of green plants, and it can also effectively monitor the dynamic changes of the ecological areas on the land surface. Fractional Vegetation Cover (FVC) is a comprehensive indicator for measuring vegetation cover, and it can reflect the characteristics of the ecological environment system. Many scholars used the NDVI and FVC to study the status of vegetation in various regions. Based on the Moderate-Resolution Image Spectro-radiometer (MODIS) NDVI data (2000-2011), climate data and mathematics algorithms, Wu et al. (2014) explored the dynamic characteristics of vegetation coverage and its causes in Qilian Mountains. Zhang et al. (2011) analyzed the relationship of NDVI dynamic changes and temperature in the Taibai Mountain Sun et al. (1998) investigated the change of surface cover in China (1985-1990) from the space and time angle, and confirmed the vegetation change and its relationship with meteorological element. The above studies provide theories and methods for the analysis of temporal and spatial variation and driving forces of vegetation cover in Changchun, China.

In recent years, the factors such as urban expansion and economic development have a great influence on the ecological environment changes in Changchun. Through the study of vegetation changes to reflect the ecological environment, it can provide scientific and reasonable support for the environmental protection in Changchun. Moreover, there have been little studies on characteristics of vegetation changing trend and its influencing factors in this area. Thus, this paper combines the NDVI and FVC to analyze the temporal and spatial change of vegetation cover and its driving factors in Changchun in 2006-2015.

\section{MATERIALS AND METHODS}

\subsection{Study Area}

Changchun is located in the northwest of Jilin Province, China at the range of $43^{\circ} 05^{\prime} \mathrm{N}-45^{\circ} 15^{\prime} \mathrm{N}, 124^{\circ} 18^{\prime} \mathrm{E}-127^{\circ} 05^{\prime} \mathrm{E}$, with an area of $20600 \mathrm{~km}^{2}$. And it is located between the humid zone in mountainous lands in the east and the semi-arid area in the western plains. There is temperate continental semi-humid monsoon climate, with an annual mean temperature of $4.8^{\circ} \mathrm{C}$ and mean annual precipitation of $522-615 \mathrm{~mm}, 2688 \mathrm{~h}$ of sunshine time. The terrain of Changchun is relatively flat, which consists of terraces and plains. The area of the terrace is about $41 \%$, while the area of the plain is about $50 \%$. The mountainous area accounts for about $9 \%$ of the total land area, mainly in Big Hack Mountain and Jilin Ha Da Mountain. The geographical location of the study area is shown in Figure 1.

\footnotetext{
${ }^{*}$ Corresponding author

Foundation project: National Natural Science Foundation Project(41271350)
} 


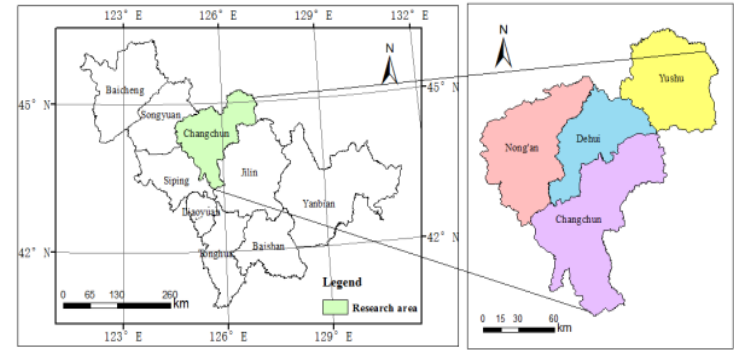

Figure 1. Geographical location of the study area

\subsection{Data Sources}

The remote sensing images selected in this paper are Landsat TM in 2006 and 2011, and Landsat OLI in 2015. As the growth of vegetation is flourishing from June to July in Northeast China, the images selected in the study are all in this period. To ensure that these images can be better used for analysis, we have applied several data processing techniques such as atmospheric correction, geometric correction, image mosaicing and clipping in the research. The administrative division of the study area does not include a small area in western Nong'an County. Temperature and rainfall data in June are obtained from open-source website (http://data.cma.cn).

\subsection{Methods}

2.3.1 NDVI: NDVI is an important index to reflect the change of vegetation cover. In terms of surface coverage, when the NDVI value is less than 0 , it means that the reflectance of clouds and water in the visible band is higher than that of the near-red band; when NDVI is close to 0 , it represents that the reflection of rock and bare soil in the two bands is roughly the same; when NDVI value is greater than 0 , it denotes that there is vegetation cover, and the vegetation cover increases with the NDVI. The NDVI calculation formula is:

$$
N D V I=\frac{N I R-R}{N I R+R}
$$

Where NDVI $=$ Normalized Difference Vegetation Index NIR = Near-Infrared Reflectivity $\mathrm{R}=$ Red Reflectivity.

2.3.2 Dimidiate Pixel Model: There is a linear correlation between vegetation coverage and NDVI, therefore the information of vegetation coverage can usually be extracted from the conversion relationship between them. In the study, we assume that the vegetation index for each pixel consists of pure vegetation and pure soil. The maximum NDVI is selected as the pure vegetation index, and the minimum NDVI is used as the pure soil vegetation index, in order to use the dimidiate pixel model to estimate vegetation coverage (Ma et al., 2014; Li, 2008), which is estimated as:

$$
f=\frac{N D V I-N D V I_{\min }}{N D V I_{\max }-N D V I_{\min }}
$$

Where $\mathrm{f}=$ vegetation coverage

$\mathrm{NDVI}_{\max }=$ the maximum value of NDVI index

NDVI $_{\text {min }}=$ the minimum value of NDVI index.

\section{RESULTS AND ANALYSIS}

\subsection{Annual Variation Tendency of NDVI}

In the remote sensing monitoring of vegetation, the existence of noise is inevitable, so confidence interval is used to solve this problem. We select the NDVI values of $95 \%$ and $5 \%$ of the cumulative frequency as the maximum and minimum values of NDVI (Li et al., 2004), and then get the changing trend of NDVI. In Figure 2, during 2006-2015, the maximum value of NDVI presented decreasing tendency. In 2015, the NDVI value decreased by $27.43 \%$ compared with that of 2006 . In addition, the decrease amplitude in 2011-2015 is more than that of 2006-2011.

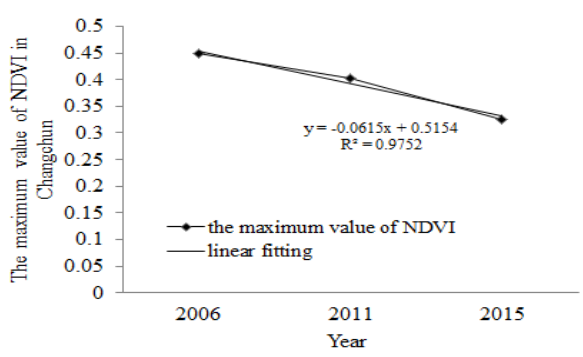

Figure 2. The changing trend graph of maximum NDVI in Changchun

\subsection{Variation Tendency of NDVI in Different Area}

The administrative division of Changchun covers a main city zone (including seven districts), two county-level cities and one county, namely Changchun, Yushu, Nong'an and Dehui. Figure 3 demonstrates the change of the maximum NDVI. In Changchun, it can be concluded that maximum NDVI in 2011 was $11.71 \%$ lower than 2006 , and the value in 2015 was $41.55 \%$ less than 2011. The NDVI values in the three regions of Yushu, Nong'an and Dehui decreased first but increased afterwards. Among them, the NDVI value of Yushu in 2011 decreased significantly, and it in 2015 increased approximately 4.6 times than 2011. The NDVI value of Nong'an had a small change range that, during 2006-2011, the NDVI in 2011 reduced by $27.93 \%$, and the NDVI in 2015 was only about $0.15 \%$ higher than 2011. In 2011, the NDVI value of Dehui had a remarkable decrease, while in 2015, it was about 2.9 times more than 2011. As a result, the vegetation index of the four regions has shown a decrease in different degrees, and the growth of vegetation has deteriorated.


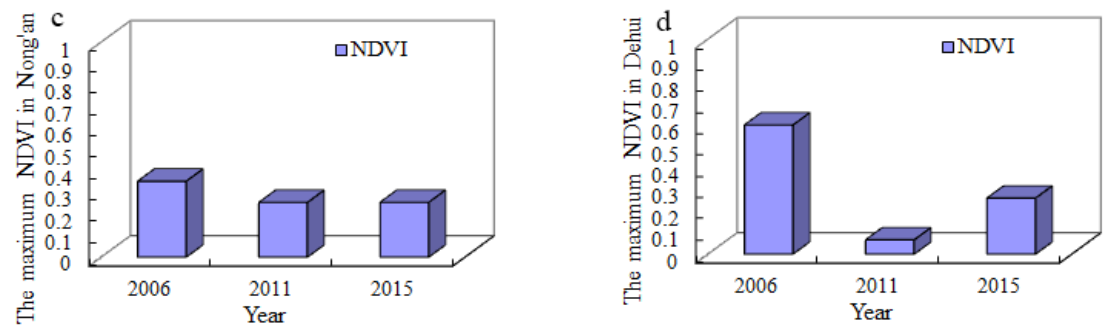

Figure 3. The change of maximum NDVI in different area of Changchun

\subsection{Annual Variation of Vegetation Cover}

In the change map (Figure 4), red indicates that the vegetation coverage is sparse while the green indicates that vegetation cover is good. Through the comparison of each year's cover, the whole vegetation coverage of Changchun in 2006 was the highest, and there is a high vegetation coverage in central, southeastern and northeastern regions. In 2011, the amount of vegetation in most areas decreased significantly. Until 2015, the whole vegetation cover increased slightly. In the past 10 years, the forest coverage in Big Hack Mountain has not shown significant changes.
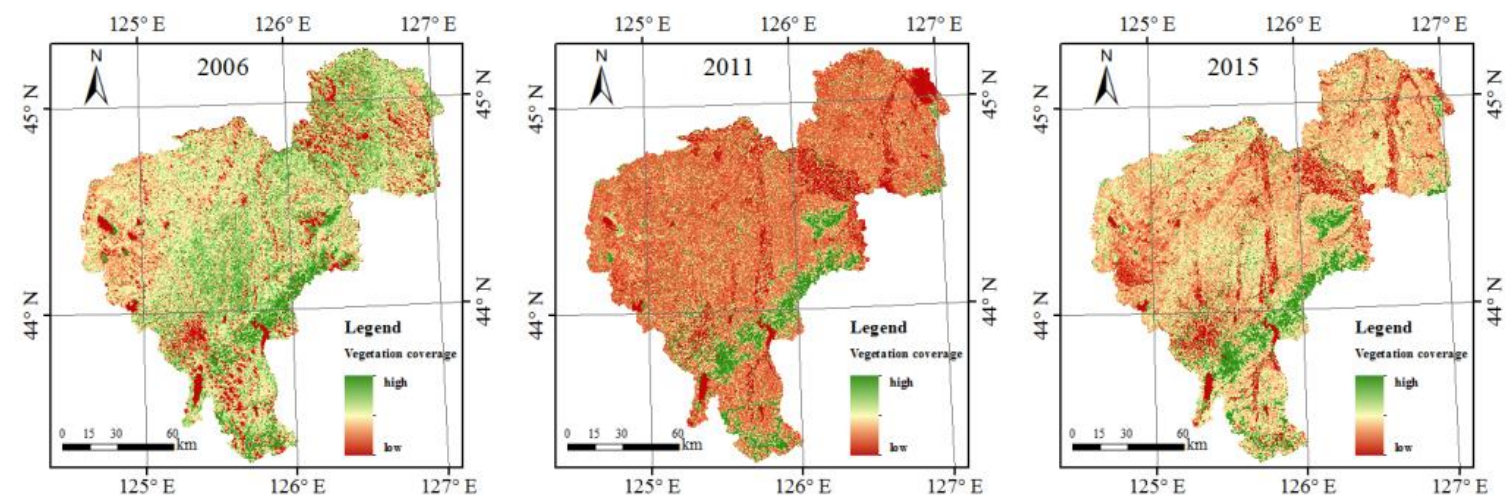

Figure 4. The change of vegetation coverage in Changchun from 2006 to 2015

\section{ANALYSIS OF THE DRIVING FORCES}

\subsection{Influence of Temperature and Precipitation}

The growth and development of vegetation need certain temperature range and precipitation (Lin, 2010). They directly affect the photosynthesis, respiration and other physiological functions of vegetation, then influence their growth. It can be seen from Figure 5 that June average temperature in Changchun was stable overall in the last 10 years, but rainfall changed greatly. Among them, the temperature changes in 2007, 2009

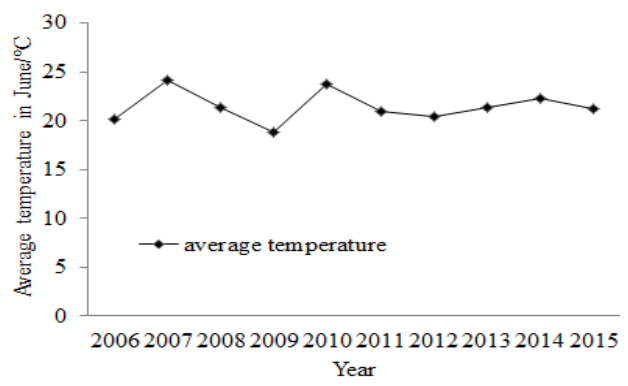

and 2010 were significant. The mean minimum temperature was $18.8^{\circ} \mathrm{C}$ in 2009 , but the mean temperature in 2007 and 2010 reached $24.1^{\circ} \mathrm{C}$ and $23.8^{\circ} \mathrm{C}$, respectively. During 2006-2011, the rainfall in other years was lower than 2006 except for 2008. And the vegetation coverage has declined during this period. From 2011 to 2015 , the temperature changed steadily and the rainfall fluctuated obviously, while the rainfall still showed an increasing trend. Combined with vegetation coverage change trend, it can be drawn that changes in temperature and rainfall have a certain effect on vegetation growth.

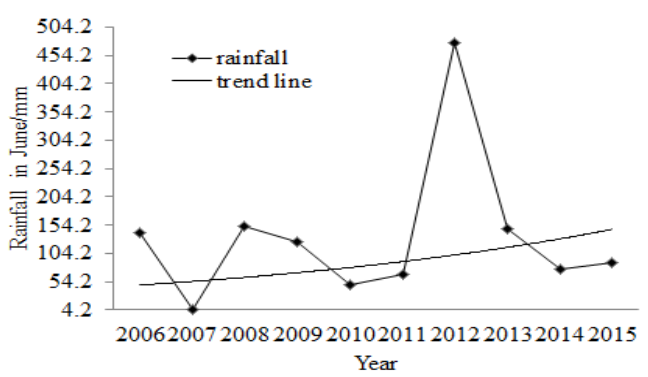

Figure 5. Average temperature and precipitation in June of Changchun from 2006 to 2015

\subsection{Influence of Human Activities}

This contribution has been peer-reviewed. 
Table 1, during 2006-2015, there was a significant increase in urban land and other land use. Urban land increased by more than $6 \%$, vegetation area decreased by more than $3 \%$, and the cultivated area decreased obviously. Among them, vegetation area first reduced by $3.98 \%$ and then increased slightly. Overall, with the development of society, urban expansion, farmland reclamation and other human activities all affected the change of vegetation coverage.

\begin{tabular}{cccccc}
\hline Time(year) & Urban land (\%) & Vegetation (\%) & farmland (\%) & Water (\%) & Others (\%) \\
\hline 2006 & 2.17 & 21.31 & 64.57 & 2.42 & 9.52 \\
2011 & 9.04 & 17.33 & 53.14 & 2.41 & 18.09 \\
2015 & 8.85 & 17.50 & 53.78 & 1.34 & 18.54 \\
\hline
\end{tabular}

Table 1. Results of land use classification in different period

\section{CONCLUSION}

Based on remote sensing and GIS technology, this paper analyzed the temporal and spatial change of vegetation cover and its driving factors in Changchun in 2006-2015. And the following results are obtained:

(1) By comparing the change of maximum NDVI, we conclude that the NDVI of Changchun has a downtrend in the last 10 years. The maximum NDVI in 2011 was about $9.93 \%$ lower than that in 2006, and the value in 2015 reduced by $19.43 \%$ compared with it in 2011.

(2) In different regions, the change trend is different, but they all show a downward trend in different degrees. The change maps of vegetation coverage created from this study show that vegetation degrades remarkably. Moreover, these changes are all related to temperature, precipitation and human activities.

(3) By analyzing the vegetation cover change from 2006 to 2015 in Changchun, we are able to better master the vegetation dynamic changes over the last 10 years in the research area. Since the monitoring of vegetation variation can indicate the state of ecological environment and climate change, the results from this paper suggest that we should strengthen ecological environment protection, promote the action of planting trees, and improve the relationship between man and nature.

\section{REFERENCES}

Li, L., 2008. Study on vegetation coverage and its dynamic change of Beijing suburbs by remote sensing - A case study of Huairou district. Beijing forestry university.

Li, M M., Wu, B F et al., 2004. Estimation of vegetation fraction in the upper basin of Miyun reservoir by remote sensing. Resources Science, 26(4), pp. 0153-0159.

Lin, N., 2010. Study on the change and drving force of vegetation cover in eastern Jilin province based of RS and GIS technology. Jilin university.

Ma, L Y., Cui, X., Feng, Q S et al., 2014. Dynamic changes of grassland vegetation coverage from 2001 to 2011 in Gannan prefecture. Acta Prataculturae Sinica, 23(4), pp. 0001-0009.

Sun, H Y., Wang, C Y., Niu Z et al., 1998. Analysis of vegetation cover change and the relationship between NDVI and environmental factors by using NOAA time series data. Journal of Remote Sensing, 2(3), pp. 204-210.

Wu, Z L., Jia, W X., Liu, Y R et al., 2014. Change of vegetation coverage in the Qilian Mountains in recent 10 years. Arid Zone
Research, 31(1), pp. 80-87.

Zhang, S H., Bai, H Y., Gao, X et al., 2011. Spatial-temporal changes of vegetation index and its responses to regional temperature in Taibai Mountain. Journal of Natural Resources, 26(8), pp. 1377-1386. 